\title{
A Dyadic Examination of Daily Health Symptoms and Emotional Well-Being in Late-Life Couples*
}

\author{
Jeremy B. Yorgason
}

David Almeida

\author{
Shevaun D. Neupert
}

Avron Spiro III
Lesa Hoffman**

\begin{abstract}
This study investigated the link between daily health symptoms and spousal emotional well-being in a sample of 96 older dyads. Higher negative mood and lower positive mood were associated with spousal symptoms in couples wherein husbands or wives reported higher average levels of symptoms. For wives, partner effects were moderated by husbands' marital satisfaction and illness severity. Specifically, higher husband marital satisfaction and illness severity were associated with higher negative mood and lower positive mood for wives on days where husbands reported higher symptom levels. In their work with later-life families, practitioners and educators should address long-term and daily health-related relationship stressors.
\end{abstract}

Key Words: health, aging, dyads, marriage, daily diary, longitudinal.

One potential consequence of age-related declines in health and physical functioning is a decrease in emotional well-being (Meeks, Murrell, \& Mehl, 2000). As health declines, depression and negative affect tend to increase, whereas life satisfaction and positive affect tend to decrease. These associations exist contemporaneously (i.e., in cross-sectional studies; Vilhjalmsson, 1998), across several days (Larsen \& Kasimatis, 1991; Watson, 1988), across months (Aneshensel, Frerichs, \& Huba, 1984; Meeks et al., 2000), and over the course of years (Heidrich \& Powwattana, 2004). Additionally, physical health problems affect emotional well-being for adults of various ages and for both men and women (Aneshensel et al., 1984; Meeks et al.; Vilhjalmsson).

Most investigations of the relationship between health and well-being have focused on the associations between health and emotional well-being of individuals. However, individuals with health problems are typically involved in a variety of relationships (see Patterson \& Garwick, 1994; Rolland \& Walsh, 2005). In couple relationships, the effects of health problems of one spouse can influence the emotional well-being of the other spouse (e.g., Bigatti \& Cronan, 2002). Although macrolinks between spousal health and marital relationships have been examined longitudinally over a number of years (Booth $\&$ Johnson, 1994), few investigators have explored the microprocesses involved in couple relationships when one spouse is sick. The purpose of the current study was to explore the daily associations of health symptoms and spousal affect for couples in later life, as well as to examine how long-term stable characteristics moderate this relationship.

\footnotetext{
*This research was supported in part by a training grant from the National Institute of Mental Health, T32 MH18904-18, Research Training in Mental Health and Aging; by a grant from the National Institute on Aging (R01-AG18436) to Dan Mroczek; and by the Clinical Science Research and Development Service of the U.S. Department of Veterans Affairs. The views expressed in this paper are those of the authors and do not necessarily represent the views of the Department of Veterans Affairs. The VA Normative Aging Study is supported by the Cooperative Studies Program/ERIC, U.S. Department of Veterans Affairs. This study is a research component of the Massachusetts Veterans Epidemiology Research and Information Center (MAVERIC). The authors thank Amy Howerter, Joyce Serido, and Matt Strobl for their assistance with data collection.

**Jeremy B. Yorgason is an Assistant Professor in the School of Family Life at Brigham Young University, Provo, UT 84602 (jeremy_yorgason@byu.edu). David Almeida is an Associate Professor at the Department of Human Development and Family Studies, The Pennsylvania State University, 105 White Building, University Park, PA 16802 (dma18@psu.edu). Shevaun D. Neupert is an Assistant Professor at the Department of Psychology, North Carolina State University, P.O. Box 7650, Raleigh, NC 27695-7650 (shevaun_neupert@ncsu.edu). Avron Spiro III, Senior Research Scientist, Normative Aging Study, VA Boston Healthcare System, Boston, MA, and Department of Epidemiology, Boston University School of Public Health, 150 South Huntington Avenue, Boston, MA 02130 (aspiro3@bu.edu). Lesa Hoffman is an Assistant Professor in the Department of Psychology, University of Nebraska-Lincoln, 238 Burnett Hall, Lincoln, NE 68588 (lhoffman@unlnotes.unl.edu).
} 


\section{Influence of Illness on Spousal Well-Being}

A number of studies have examined how the stressors of an illness can influence spousal well-being. Some researchers have suggested that illness may negatively influence spousal physical and mental health in non-care providing situations (Bigatti \& Cronan, 2002). The influence of illness on spousal well-being is also supported by research on detrimental effects of caregiving for a spouse with physical and mental chronic illnesses (Schulz, Visintainer, \& Williamson, 1990). Different mechanisms may be involved for spousal caregivers, as opposed to persons whose spouse does not require assistance with activities of daily living. Specifically, caregivers likely have additional strain from the tasks related to caring for a sick loved one. It is not surprising, then, that caregivers often experience psychological stress (for a review, see Schulz et al.). Longitudinal studies of spousal caregiving have indicated a positive association between illness and spousal reports of depression and anxiety over various spans of time, ranging from weeks to years (Beach, Schulz, Yee, \& Jackson, 2000; Cannuscio et al., 2002; Grunfeld et al., 2004; Jang, Clay, Roth, Haley, \& Mittelman, 2004).

Whether considering spousal caregiving, which is more likely to occur in late life, or the effects of illness on noncaregiving spouses, we are not aware of any investigations of daily influences of symptoms on spousal well-being. More specifically, researchers have not examined the proximal daily influences of illness in combination with more distal, long-term illness influences. To begin to address this issue, we used a daily diary design to assess the within-couple associations of health symptoms and well-being over time. By asking respondents to report on symptoms and emotional well-being close to the time they were experienced (i.e., during the past $24 \mathrm{hr}$ ), the research design reduced recall bias and allowed for a proximal assessment of symptom/well-being links (Almeida, 2005; Larson \& Almeida, 1999).

\section{Conceptual Framework: Couple Stress and Emotional Transmission Processes}

Our investigation of the effects of daily health symptoms on spousal well-being is founded on Karney and Bradbury's (1995) "vulnerability-stress-adaptation" model and the research paradigm of emotion transmission in families (Larson \& Almeida, 1999).
Within the vulnerability-stress-adaptation model, stressful events influence the quality and stability of marriage, depending on how couples adapt. Adaptation processes are influenced not only by the stressors themselves but also by "enduring vulnerabilities," or characteristics and traits that do not change from day to day. We examined the link between the stressor events of daily health symptoms and daily spousal emotional well-being, along with how this relationship is moderated by the enduring vulnerabilities of chronic illness and marital satisfaction.

According to Larson and Almeida (1999), emotional transmission occurs when "events or emotions in one family member's experience show a consistent predictive relationship to subsequent emotions or behaviors in another family member" (p. 5). The key to this approach is examining the transmission of distress among family members as it unfolds over brief intervals of time, typically assessed throughout the day or from one day to the next. Studies using this approach examine how reports from multiple family members are related. As presented by Larson and Almeida, our study used the "concurrent model" of emotion transmission to examine the effects of health symptoms on spousal affect reported on the same day. We addressed the question of whether a spouse reports lower levels of emotional well-being on days when a participant reports more health symptoms, compared to days with fewer symptoms.

\section{Moderators of the Health to Well-Being Relationship}

Research on vulnerability-stress-adaptation and emotion transmission often posits between-couple moderators of transmission. In this study, we tested three possible moderators: gender, marital satisfaction, and severity of chronic illness conditions. Previous research suggests that the transmission of emotions in couple relationships most often originates in husbands and is transferred to wives, rather than vice versa (Larson \& Almeida, 1999). Furthermore, wives report more high-stress days and fewer distress-free days than husbands (Almeida \& Kessler, 1998). This idea is consistent with marriage and health research, which suggests that women rate the impact of illness on the relationship more strongly than do men (Burman \& Margolin, 1992; KiecoltGlaser \& Newton, 2001). This effect may be because of husbands being senders of emotions, wives 
being receivers of emotions, or some combination of both (Larson \& Almeida). Few researchers have considered the influence of gender on the relationship between health problems and emotional well-being of couples in late life, when health problems are generally expected.

Also related to emotional transmission, Larson and Almeida (1999) suggested that persons dealing with chronic stress are more likely to send and receive negative emotions. For example, spouses may respond differently when they are more or less satisfied in their marriage. Kiecolt-Glaser and colleagues found that lower marital quality was related to a decrease in immune functioning (KiecoltGlaser, 1999; Kiecolt-Glaser, Glaser, Cacioppo, \& Malarkey, 1998). Wickrama, Lorenz, Conger, and Elder (1997) found that increased marital satisfaction was related to improved health over time. Other findings suggest that marital satisfaction is related to fewer reports of health symptoms and fewer doctor visits (Barnett, Davidson, \& Marshall, 1991; Prigerson, Maciejewski, \& Rosenheck, 2002). Although couples in long-term marriages have navigated many of life's ups and downs, not all long-term relationships are necessarily happy (VanLaningham, Johnson, \& Amato, 2000). Thus, we expected some variation in marital satisfaction in the present older adult sample and that marital satisfaction would influence the effects of daily health symptoms on emotional well-being.

Chronic illness may also moderate the association between spousal symptoms and emotional wellbeing. Spouses with a chronic condition are likely to have flare-ups and acute bouts from an illness, as well as time, energy, and money being spent on managing the illness (Loeb, Penrod, Falkenstern, Gueldner, \& Poon, 2003; Vilhjalmsson, 1998). Realities of chronic conditions may accumulate and have a magnified negative impact on couple relationships.

\section{Hypotheses}

1. Daily health symptoms will have a negative association with spousal mood.

2. As women and men experience emotions differently, we expected that the daily health symptoms would predict mood differently for each. Further, as suggested by the literature, we hypothesized that wives would be more sensitive to the effects of spouses' daily symptoms than their husbands.
3. As marital satisfaction may be a risk or protective factor to health-related stressors, we expected that it would moderate the link between daily symptoms and spousal mood. Specifically, we hypothesized that the negative effects of daily health symptoms would be greater for those with lower marital satisfaction.

4. As chronic health conditions may exacerbate the effects of daily symptoms, we expect that illness severity would moderate the associations between daily symptoms and spousal mood. Specifically, we hypothesized that the negative effects of daily health symptoms would be greater for those with greater illness severity.

\section{Method}

\section{Sample}

Data were from participants of the VA Normative Aging Study (NAS), a longitudinal study of aging in men. The NAS was founded at the Boston VA Outpatient Clinic in 1963 (Bossé, Ekerdt, \& Silbert, 1984). Initial screening was conducted with over 6,000 men, resulting in a panel of 2,280 men who were initially physically and mentally healthy. NAS participants have returned for medical examinations and testing every 3-5 years, depending on their age. Baseline data in the current study were collected from a mail survey completed by active participants and their wives in 2001.

Between August 2002 and April 2003, 529 people (NAS respondents and their wives) were contacted and invited to participate in the daily diary study. Of these, 374 agreed, and a total of 333 individuals returned usable surveys. Most participants completed all 8 days of the study. For a more detailed description of data collection procedures, see Neupert, Almeida, Mroczek, and Spiro (2006). Data for this study included daily surveys only if they were completed by both spouses on the same day, resulting in usable data from 192 individuals (96 dyads), for a total of 649 days. Average ages of participants in the study were 77 for men (range $=61-88$ years) and 71 for women (range $=44-88$ years).

\section{Measures}

Daily affect. The Positive and Negative Affect Schedule (PANAS; Watson, Clark, \& Tellegen, 1988) 
was used to measure daily affect. The PANAS is a measure that consists of a 10 -item positive mood scale and a 10-item negative mood scale. The scales contain adjectives that describe different feelings and emotions (e.g., upset, enthusiastic), and participants were asked to indicate to what extent they felt each of the emotions on the day they completed the survey. Responses ranged from 1 (very slightly or not at all) to 5 (extremely). The PANAS scales have demonstrated acceptable internal consistency reliabilities, with alphas ranging from .84 to .90 (Watson et al., 1988). The alpha coefficients for the current sample were .92 and .95 for husband and wife positive affect, respectively, and .84 for both husband and wife negative affect (see Table 1 for correlations and descriptive information related to study variables).

Daily physical symptoms. Daily physical symptoms were measured using a shortened version of Larsen and Kasimatis' (1991) physical symptom checklist. The 13-item scale assessed symptoms such as aches/pain (headaches, backaches, and muscle soreness), gastrointestinal symptoms (poor appetite, nausea/upset stomach, constipation/diarrhea), chest pain or dizziness (symptoms often associated with cardiovascular functioning), and upper respiratory infection symptoms (sore throat, runny nose, congestion). Two additional items (cold/flu symptoms and joint pain) were also included in the checklist. Each day, the respondents indicated whether they experienced each symptom over the past $24 \mathrm{hr}$. Items were summed, with higher scores reflecting reports of more symptoms for each day.

Marital satisfaction. Global marital satisfaction was measured using the Dyadic Adjustment Scale (DAS; Spanier, 1976), which is a 32-item scale that assesses four different areas of marital relationships, including satisfaction, consensus, cohesion, and affectional expression. A summary score (ranging from 0 to 151) from the subscales provides an overall indication of marital adjustment. The DAS has high internal consistency (.90) and test-retest reliability (.87), and good construct validity (Carey, Spector, Lantinga, \& Krauss, 1993; Crane, Allgood, Larson, \& Griffin, 1990). It also discriminates between distressed and nondistressed couples (Eddy, Heyman, \& Weiss, 1991). In this study, a revised version of the DAS (RDAS) comprising 14 items (Busby, Christensen, Crane, \& Larson, 1995) was used during the NAS survey of 2001 to provide a baseline measure of marital satisfaction for each spouse (husband, $\alpha=.82$; wife, $\alpha=.83$ ). The RDAS (range $=0-69$ ) has a recommended cutoff score of 48, suggesting that those scoring below this level have distressed relationships (Crane, Middleton, \& Bean, 2000).

Chronic illness. The presence of chronic illness was assessed by asking respondents if they had any physical condition, illness, or health problem that currently bothered them. Severity of illnesses reported was determined by the modified Wyler's Seriousness of Illness Rating Scale (SIRS; Bossé, Aldwin, Levenson, \& Ekerdt, 1987). This scale rates a variety of illnesses on the basis of their severity, with scores ranging from 0 (no illness reported) to 124 (life-threatening malignancy). Rosenberg, Hayes, and Peterson (1987) reported high interrater reliability of the SIRS for a sample of medical students, residents, and faculty at a medical school (concordance coefficient of .72). Although related to daily physical symptoms, this measure provides

Table 1. Correlations and Distributional and Scale Properties of Dependent and Independent Variables ( $N=96$ Couples)

\begin{tabular}{lccccc}
\hline Variables & 1 & 2 & 3 & \multicolumn{1}{c}{4} & \multicolumn{1}{c}{5} \\
\hline 1. Positive mood & $.20^{* * *}$ & $-.21^{* * *}$ & $-.24^{* * *}$ & $.16^{* * *}$ & $-.19^{* * *}$ \\
2. Negative mood & -.07 & $.19^{* * *}$ & $.30^{* * *}$ & .01 & .08 \\
3. Daily symptoms & $-.29^{* * *}$ & $.18^{* * *}$ & $.21^{* * *}$ & $.10^{*}$ & $.34^{* * *}$ \\
4. Marital satisfaction & $.24^{* * *}$ & $-.16^{* * *}$ & -.03 & $.37^{* * *}$ & $.20^{*}$ \\
5. Illness severity & $-.12^{*}$ & .03 & .03 & .03 & $.30^{* * *}$ \\
Husband, $M(S D)$ & $26.83(10.07)$ & $11.85(3.30)$ & $1.53(1.41)$ & $54.56(6.42)$ & $79.52(39.39)$ \\
Wife, $M(S D)$ & $28.76(10.05)$ & $12.77(4.34)$ & $1.69(1.46)$ & $54.11(7.41)$ & $71.98(29.86)$ \\
$t$ values & $3.36^{* * *}$ & $4.63^{* * *}$ & $2.38^{*}$ & 1.49 & -.027
\end{tabular}

Note. Wife correlations above the diagonal, husband correlations below the diagonal, and correlations between husband and wife scores on the diagonal. $t$ values are based on paired sample $t$ tests comparing husband and wife means.

$* p \leq .05 . * * p \leq .01 . * * * p \leq .001$. 
a more stable health assessment, as well as an indication of chronic illness severity.

\section{Analyses}

Multivariate multilevel models (Snijders \& Bosker, 1999) were estimated using the mixed procedure (PROC MIXED) in SAS to examine the relationships between daily symptoms for husbands and wives and daily spousal affect. This approach takes into account the longitudinal (correlated residuals within an individual across time) as well as dyadic (spouses nested within couples) nature of the data (see Lyons \& Sayer, 2005; Raudenbush, Brennan, \& Barnett, 1995) and allowed for an examination of dependent variables for both spouses to be estimated simultaneously while "controlling for within-dyad dependence of observations" (Lyons \& Sayer, 2005, p. 1050). The current approach differs from that used by Lyons and Sayer, as well as others (e.g., Barnett, Marshall, Raudenbush, \& Brennan, 1993; Raudenbush et al., 1995), however, in that it did not include time as a predictor in the model. That is, it was not a "growth curve" analysis where a systematic trend across time was expected but rather an examination of variation or fluctuation across time, focusing on the covariation of symptoms and mood on a given day.

The Level 1 within-couple model specifies the relationship between spousal mood and symptoms over time. Husband and wife symptoms were transformed into two variables representing between- and within-couple variation, which were then predictors at Level 2 and Level 1, respectively. Between-couple variation was represented by the mean symptoms across days, which was centered on a meaningful value near the group mean (two symptoms for this sample). Within-couple variation was represented by the deviation from a person's average on a given day and thus represented daily fluctuation relative to participants' usual level. As a result, we were able to examine both the between- and within-couple relationships of symptoms and mood.

The Level 2 between-couple model specified main effects of between-person symptoms (as described above), spousal marital satisfaction and illness severity on spousal mood, and cross-level interactions of these moderators with daily symptoms on spousal mood. Marital satisfaction was centered at 50 and illness severity at 80 (values near the mean) in order to improve interpretation of the intercepts.
Random intercepts were estimated in the models; yet, because they did not generally improve the model, random slopes were not estimated. Equations and descriptions of the complete model are presented in Appendix A.

\section{Results}

\section{Descriptive Statistics}

Descriptive information is presented for husbands and wives in Table 1. In order to assess average level of symptoms and emotional well-being, an initial set of analyses aggregated positive affect, negative affect, and daily symptoms across the 8 study days. Wives reported significantly higher average levels of positive affect, negative affect, and physical symptoms than their husbands. Spouses did not differ significantly in their mean levels of marital satisfaction and illness severity. Table 1 also presents correlations of these variables between spouses (on the diagonal), all of which were modestly correlated. Correlations among the study variables are also shown for husbands (below diagonal) and wives (above diagonal). These correlations were computed using the personperiod data set, thus including both between- and within-couple variations. For wives, the strongest correlations were found between negative mood and daily symptoms and between illness severity and daily symptoms. A less intuitive finding is that wives' marital satisfaction was positively correlated with reports of daily symptoms. For husbands, the highest correlation was between positive mood and daily symptoms. Interestingly, for husbands, there was no correlation between positive and negative mood. Furthermore, husbands' illness severity was generally not related to other study variables.

\section{Within-Couples Daily Analyses}

A multivariate approach was used to assess the within-couple association of husbands' and wives' physical symptoms with their positive and negative affect, as well as moderating effects of spousal marital satisfaction and illness severity. An empty model for the four outcomes was first estimated to examine within-couple correlations of husbands' and wives' positive and negative moods. Significant withincouple variation was found for positive and negative mood for husbands and wives. The residuals for 
husbands' and wives' negative mood were somewhat correlated $(r=.22, p<.001)$; yet, corresponding residuals for positive mood were uncorrelated $(r=$ $.06, p>.05)$. A series of models were then estimated, beginning with between- and within-couple predictors of husbands' and wives' daily physical symptoms. "Actor" and "partner" daily predictors were included to assess partner effects while controlling for one's own symptoms. Main effects for Level 2 predictors were then added, followed by cross-level interactions of illness severity and marital satisfaction in separate models.

As shown in Table 2, positive mood was lower and negative mood was higher for wives with higher average symptoms. Also, wives' negative mood was higher on days where they reported greater-thanaverage symptoms. The same pattern between symptoms and mood was found for husbands. The only significant "partner" effect was the association between higher average wives' symptoms and lower husband positive mood. These daily main effects were interpreted in the context of the corresponding Level 2 covariate, marital satisfaction, because a higher order interaction with marital satisfaction was in the model. Specifically, these daily associations were significant for couples at the marital satisfaction centering point (50).

Regarding marital satisfaction, positive mood was greater for wives with greater marital satisfaction (see Table 2). Wives' positive mood was also related to a cross-level interaction of husband average daily symptoms and marital satisfaction. A plot of this relationship (shown in the top panel of Figure 1) illustrates that husband average daily symptoms had a stronger negative relationship with wives' positive mood in couples with greater husband marital satisfaction. Wives' negative mood was greater in wives with less marital satisfaction and in wives with husbands of greater marital satisfaction. Neither dimension of husbands' mood was related to their own or to their wives' marital satisfaction.

Wives' positive mood was not related to own or spousal physical symptoms or baseline illness severity (Table 3). Wives' negative mood, however, was higher on days with an increase in their own average daily symptoms and for those with higher average daily symptoms. Wives' negative mood was also higher in couples where husbands reported greater average daily symptoms. Again, this main effect was interpreted in the context of the Level 2 covariate, illness severity. Specifically, the "partner" effect of higher husband symptoms on wives' negative mood was significant at the centering point of illness severity (80 in this model). The magnitude of this effect was stronger for husbands with higher illness severity, as shown in the bottom panel of Figure 1. However, wives' negative mood was not related to daily fluctuations in husband symptoms. Positive mood was greater in husbands with fewer average daily symptoms, but no spousal effects were significant. Husbands' negative mood was greater on days with an increase in their own average daily symptoms and

Table 2. Multivariate Model of Mood Predicted by Daily Symptoms, Baseline Marital Satisfaction, and Interactions Between Daily and Baseline Predictors ( $n=62$ Couples, With 1,655 Observations)

\begin{tabular}{|c|c|c|c|c|c|c|c|c|}
\hline \multirow[b]{2}{*}{ Variables } & \multicolumn{4}{|c|}{ Wife Mood } & \multicolumn{4}{|c|}{ Husband Mood } \\
\hline & \multicolumn{2}{|c|}{ Positive $B(S E)$} & \multicolumn{2}{|c|}{ Negative $B(S E)$} & \multicolumn{2}{|c|}{ Positive $B(S E)$} & \multicolumn{2}{|c|}{ Negative $B(S E)$} \\
\hline Intercept & $26.79 * *$ & $(1.49)$ & $13.59 * * *$ & $(.55)$ & $23.67 * *$ & $=(1.55)$ & $12.34 * * *$ & $(.33)$ \\
\hline W within symptoms & -0.16 & $(.36)$ & $0.48^{*}$ & $(.22)$ & 0.66 & $(.37)$ & -0.18 & $(.31)$ \\
\hline W between symptoms & $-2.50 * *$ & $(.80)$ & $1.03 * * *$ & $(.29)$ & $-2.73^{* *}$ & $(1.01)$ & 0.39 & $(.22)$ \\
\hline $\mathrm{H}$ within symptoms & 0.40 & $(.52)$ & 0.22 & $(.31)$ & -0.18 & $(.16)$ & $0.40 * *$ & $(.15)$ \\
\hline H between symptoms & 0.56 & $(1.02)$ & 0.30 & $(.37)$ & $-2.67 * *$ & $(.84)$ & $0.38 *$ & $(.18)$ \\
\hline W marital satisfaction & $0.32 *$ & $(.16)$ & $-0.16 * *$ & $(.06)$ & 0.15 & $(.18)$ & -0.03 & $(.04)$ \\
\hline $\mathrm{H}$ marital satisfaction & -0.08 & $(.17)$ & $0.17 * *$ & $(.06)$ & 0.31 & $(.17)$ & -0.02 & $(.04)$ \\
\hline W Marital Satisfaction $\times$ W Within Symptoms & & & & & -0.04 & $(.04)$ & 0.01 & $(.03)$ \\
\hline W Marital Satisfaction $\times$ W Between Symptoms & & & & & 0.12 & $(.12)$ & -0.03 & $(.03)$ \\
\hline H Marital Satisfaction $\times$ H Within Symptoms & -0.03 & $(.04)$ & -0.02 & $(.03)$ & & & & \\
\hline H Marital Satisfaction $\times$ H Between Symptoms & $-0.32 *$ & $(.14)$ & 0.08 & $(.05)$ & & & & \\
\hline
\end{tabular}

Note. $B=$ unstandardized estimates; $S E=$ standard error; $\mathrm{W}=$ wife; $\mathrm{H}=$ husband.

${ }^{*} p \leq .05 .{ }^{* *} p \leq .01 .{ }^{* * *} p \leq .001$. 
for those with greater average daily symptoms, but no spousal effects were significant.

\section{Discussion}

Experiencing health problems in later life can be viewed as normative; yet, older couples may still struggle with health-related stresses and adjustments. In the current study, we examined the relationship between daily health symptoms and spousal mood, using the vulnerability-stress-adaptation model (Karney \& Bradbury, 1995), as well as the paradigm of emotional transmission (Larson \& Almeida, 1999). We expected that higher symptoms on a given day would be related to higher negative or lower positive mood levels. Results partially supported our theoretical framework; however, we found between-couple rather than within-couple differences. Specifically, greater levels of negative mood were found in wives of husbands with higher average symptom reports, and lesser levels of positive mood were found in husbands of wives with higher average symptom reports. Moreover, the association between husband health symptoms and wife mood was moderated by marital satisfaction and chronic illness severity. These findings contribute to a growing body of literature examining the relationship between spousal health and emotional well-being. Specifically, researchers have suggested that emotional transmission related to health problems occurs and that the transmission processes are different depending on gender, marital satisfaction, and the presence of a chronic illness (Larson \& Almeida).

\section{Daily Symptoms Influencing Spousal Mood}

In partial support of our hypotheses, and congruent with the research literature, gender has a moderating effect on the daily symptom with mood relationship (Burman \& Margolin, 1992; Kiecolt-Glaser \& Newton, 2001). Specifically, husbands' daily symptoms were linked to wives' negative mood. Also, husbands' positive mood was lower for couples wherein wives reported more symptoms. Both of these findings support the emotional transmission paradigm for those with higher average symptoms. Our model where wives' symptoms were related to lower levels of husbands' positive mood was interpreted in the context of husband reports of marital

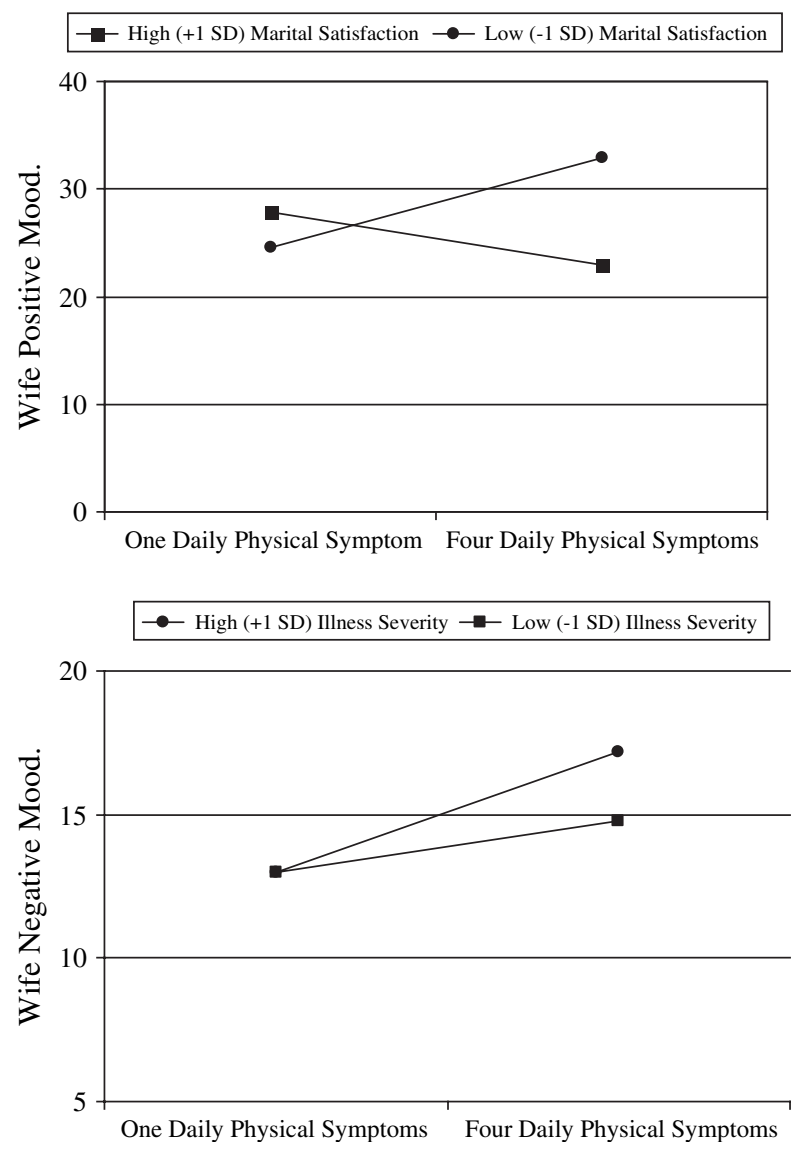

Figure 1. Cross-Level Interaction Effects of Husband Baseline Marital Satisfaction $\times$ Daily Husband Symptoms on Wife Daily Positive Mood (Top Panel), and Husband Baseline Chronic Illness Severity $\times$ Daily Husband Symptoms on Wife Daily Negative Mood (Bottom Panel).

satisfaction. In contrast, the association between husbands' symptoms and wives' negative mood was interpreted in the context of husbands' illness severity levels. Because these models do not include the exact same number of couples and observations, and because marital satisfaction and illness severity are not correlated for husbands, it is difficult to compare these relationships directly. In essence, we have no reason to suspect that couples with average husband marital satisfaction are similar to those with average illness severity. Despite these limitations, it is interesting that there are a greater number of "partner effects" between husbands' reports (health and marital satisfaction) and wives' mood. These gender differences may be interpreted as a power issue, with men exerting influence over their wives, as differences in the boundaries and processes related to emotions in men and women or as some 
Table 3. Multivariate Model of Mood Predicted by Daily Symptoms, Baseline Illness Severity, and Interactions Between Daily and Baseline Predictors ( $N=72$ Couples, With 1,869 Observations)

\begin{tabular}{|c|c|c|c|c|c|c|c|}
\hline \multirow[b]{2}{*}{ Variables } & \multicolumn{4}{|c|}{ Wife Mood } & \multicolumn{3}{|c|}{ Husband Mood } \\
\hline & \multicolumn{2}{|c|}{ Positive $B(S E)$} & \multicolumn{2}{|c|}{ Negative $B(S E)$} & \multicolumn{2}{|c|}{ Positive $B(S E)$} & Negative $B(S E$ \\
\hline Intercept & $25.71 *$ & $(1.52)$ & $13.97 * *$ & $(.52)$ & $24.51 *$ & $(1.70)$ & $12.00 * * *(.34)$ \\
\hline W within symptoms & -0.34 & $(.29)$ & $.66 * *$ & $(.18)$ & -.17 & $(.27)$ & $-.17 \quad(.18)$ \\
\hline W between symptoms & -1.28 & $(.79)$ & $.65^{* *}$ & $(.27)$ & -.07 & $(.94)$ & $-.05 \quad(.18)$ \\
\hline $\mathrm{H}$ within symptoms & -0.04 & $(.30)$ & -.25 & $(.22)$ & -.22 & $(.16)$ & $.47 * * *(.14)$ \\
\hline H between symptoms & -0.27 & $(1.12)$ & $1.00^{* *}$ & $(.36)$ & $-1.88^{*}$ & $(.90)$ & $.38 * \quad(.18)$ \\
\hline W illness severity & -.05 & $(.03)$ & .01 & $(.01)$ & .00 & $(.03)$ & $(.00)$ \\
\hline H illness severity & -.03 & $(.02)$ & .01 & $(.01)$ & -.03 & $(.02)$ & $(.01)$ \\
\hline $\begin{array}{l}\text { W Illness } \times \text { W Within } \\
\text { Symptoms }\end{array}$ & & & & & -.01 & $(.01)$ & $(.00)$ \\
\hline $\begin{array}{l}\text { W Illness } \times \text { W } \\
\text { Between Symptoms }\end{array}$ & & & & & .00 & $(.02)$ & $(.00)$ \\
\hline $\begin{array}{l}\text { H Illness Severity } \times \mathrm{H} \\
\text { Within Symptoms }\end{array}$ & .00 & $(.01)$ & -.01 & $(.01)$ & & & \\
\hline $\begin{array}{l}\text { H Illness Severity } \times \mathrm{H} \\
\text { Between Symptoms }\end{array}$ & .00 & $(.02)$ & $.01^{*}$ & $(.01)$ & & & \\
\hline
\end{tabular}

Note. $B=$ unstandardized estimates; $S E=$ standard error; $\mathrm{W}=$ wife; $\mathrm{H}=$ husband. ${ }^{*} p \leq .05 .{ }^{* *} p \leq .01 . * * * p \leq .001$.

combination of these factors (Larson \& Almeida, 1999). Some researchers have suggested that a redistribution of power occurs in later-life couple relationships, with women becoming more assertive and men becoming more emotionally involved (e.g., Miller, Hemesath, \& Nelson, 1997). However, findings from the current study suggest that genderrelated emotional transmission processes in older couples are similar to those in their younger counterparts (see Almeida \& Kessler, 1998). In the family gerontology literature, this finding supports the notion that caregiver wives experience greater burden than caregiver husbands, regardless of whether they are caring for a spouse with dementia or a physical illness (Barusch \& Spaid, 1989). One interpretation of this gender difference is that wives may provide more caregiving tasks or may be more greatly influenced by work-related role strains and insufficient resources than husband caregivers (Kramer \& Kipnis, 1995). Further research is necessary to explore alternative "external" aspects of couples' lives potentially influenced by their health symptoms, such as spouses spending time in nonfamily activities, including alcohol consumption, smoking, or spending.

Second, gender differences exist for the average levels of positive mood, negative mood, and reports of daily health symptoms. In contrast, men and women report similar marital satisfaction and chronic illness severity. That men and women report similar global marital satisfaction scores seems intuitive as reports reflect an assessment of something spouses have in common. It might be less expected for spouses to report similar levels of illness severity. Interpretations of this correlation are that spouses share or are influenced by each others' health habits (Lewis, Rook, \& Schwarzer, 1994; Osler, 1998), and that spouses often experience health problems resulting from caregiver strain (Pinquart \& Sörensen, 2005). Future research should explore spousal patterns of morbidity and daily symptoms.

\section{Moderating Effects of Marital Satisfaction and Chronic Illness Severity}

In support of our third and fourth hypotheses, we found that marital satisfaction and chronic illness severity are important factors in identifying for whom symptoms are associated with spousal mood. For husbands with lower average symptom levels, there is no relation to wives' reports of positive mood, regardless of husbands' marital satisfaction. However, for husbands with higher average symptom 
levels, higher husband marital satisfaction is related to lower reports of wives' positive mood, and lower husband marital satisfaction is related to higher reports of wives' positive mood. This finding suggests that marital satisfaction influences the perception of daily symptoms for some couples. Contrary to our hypothesis, lower marital satisfaction is not necessarily an "enduring vulnerability" as defined by Karney and Bradbury (1995). Rather, the stress from daily symptoms seems to negatively influence couples where husbands report higher marital satisfaction. One interpretation of the mechanisms operating here might be that on high-husband symptom days, couples have more negative interactions. For husbands with higher marital satisfaction, negative interaction could be related to lower levels of wives' positive mood. For husbands with lower marital satisfaction, perhaps more negative interaction might simply equate to more interaction than is typical, leading to greater closeness for couples. An alternative interpretation is that less interaction may occur on days with higher husband symptoms, thus leading to less positive interaction for those with higher marital satisfaction, but less negative interaction for those with lower marital satisfaction. In general, these results reveal the potential power of both proximal (daily) and distal (enduring vulnerability) experiences in relation to individual and relationship well-being.

Although health problems in later life may be normative, individual differences in illness severity can play an important role in spousal well-being. Indeed, results from this study support the hypothesis that chronic illness moderates the relationship between daily health symptoms and spousal mood. In the context of the vulnerability-stress-adaptation model, it appears that severity of chronic illnesses, even in later life, presents an enduring vulnerability. Specifically, the adaptive processes that couples experience seem to be doubly constrained on highhusband symptom days for couples wherein husbands report higher illness severity. Future research is warranted that examines the cumulative effects related to daily health symptoms resulting from specific illnesses, for both husbands and wives. Furthermore, researchers may wish to examine whether chronic, daily, or both stressors lead to decreased immune functioning (Kiecolt-Glaser, 1999), whether comorbid chronic illnesses have cumulative effects on relationships, and how objective health reports might clarify daily effects of health problems.

\section{Implications for Practice and Education}

Results from this study have practical implications for family clinicians and educators. First, related to gender, results support the "same old story" of wives being more aware of and sensitive to their husbands' experiences, than vice versa (Almeida $\&$ Kessler, 1998; Hagedoorn et al., 2001). This is true of husbands with higher average symptoms, in addition to baseline wives' marital satisfaction and husbands' illness severity, suggesting that family professionals, clinicians, and health care providers can expect that gender will influence responses to illness. Therefore, professionals should strive to educate couples about gender differences and assess related relationship distress.

Although the original NAS sample was recruited on the basis of good health, study respondents report an average of approximately two symptoms per day. Significant spousal health influences are between-couple differences, suggesting that persons with a higher average number of symptoms more negatively influence spousal mood. Therefore, clinicians or educators working with persons who experience higher average levels of daily symptoms might expect to encounter stronger links between health and spousal well-being. In addition to the number of health symptoms individuals experience, innumerable permutations of symptom combinations exist. Future research needs to address specific symptom combinations, such as those experienced in the case of commonly co-occurring, age-related chronic illnesses (e.g., diabetes and arthritis).

The moderating influence of husbands' marital satisfaction on the husbands' symptoms with wives' positive mood relationship also has implications for intervention and education. Results suggest that it is husbands with more highly satisfied couple relationships whose wives' positive mood is more strongly related to their husbands' daily symptoms. However, highly satisfied couples are not traditionally targeted in intervention efforts. Recent developments in marriage education could provide helpful services for couples in preventative settings (see Larson, 2004). For example, Bodenmann and Shantinath (2004) described the Couples Coping Enhancement Training program, an educational program that is based on the stress and coping model with a specific aim of preventing marital distress. Such programs could recruit couples prior to experiencing specific stressors (e.g., illness), to assist in dealing with potential future stressful events. 
The moderating effects of husbands' illness severity on the husbands' symptoms to wives' negative mood relationship also has implications for biopsychosocial interventions (see Rolland \& Walsh, 2005; Schmalling \& Sher, 2000). In this case, couples where the husband has a severe chronic illness and experienced high levels of daily health stressors would be the targets for intervention. Educating couples about the daily emotional stresses that often accompany spousal illness could be a starting point for intervention. Such intervention could occur through health care providers at the time of diagnosis or treatment, through family therapists providing treatment to couples wherein a spouse has a chronic illness, and through family educators who work with older adult populations or their family members.

\section{Limitations, Strengths, and Conclusions}

Because the diaries were sent and returned all at once, and were self-administered, we cannot be certain that participants followed the exact instructions regarding diary completion (i.e., at the end of each day, about $30 \mathrm{~min}$ before going to bed). However, on the basis of previous research noting high levels of compliance with paper diaries when only one assessment per day is required (e.g., Sherliker \& Steptoe, 2000), and given the NAS participants' history of compliance with this study over the past 40 years (of the survivors, over $90 \%$ are continuing participants, most of the men who are continuing participants report to the Boston VA every 3 years for a biomedical exam and complete a number of questionnaires either mailed a month in advance or administered the day of the exam), it is unlikely that they waited until the eighth day to complete all their diaries.

The study would benefit from an improvement in the measurement of marital satisfaction. Although the RDAS provides a good measure of global relationship satisfaction, using a measure of multiple dimensions of marital quality (see Johnson, White, Edwards, \& Booth, 1986) would provide greater insight into specific aspects of couple relationships associated with daily health stressors. Furthermore, assessments of daily marital interactions (see McNulty \& Karney, 2001) could provide insight into how microlevel relationship functioning might influence the relationship between symptoms and spousal mood.

Despite these limitations, this study has strengths in its inclusion of long-term as well as daily measures, in its inclusion of data from both spouses in each couple, and its use of statistical methods that take into account the correlated nature of dyadic longitudinal data. Practitioners and educators that work with couples in late life need to be aware of and elucidate health-related stressors that occur from one day to the next. This is especially true in couples with poorer average daily health. Future research with later-life samples experiencing individual and multiple chronic illnesses is needed to better understand how older couples adjust on a daily basis to age-related health problems.

\section{References}

Almeida, D. M. (2005). Resilience and vulnerability to daily stressors assessed via diary methods. Current Directions in Psychological Science, 14, 64-68.

Almeida, D. M., \& Kessler, R. C. (1998). Everyday stressors and gender differences in daily distress. Journal of Personality and Social Psychology, 75, 670-680.

Aneshensel, C. S., Frerichs, R. R., \& Huba, G. J. (1984). Depression and physical illness: A multiwave, nonrecursive causal model. Journal of Health and Social Behavior, 25, 350-371.

Barnett, R. C., Davidson, H., \& Marshall, N. L. (1991). Physical symptoms and the interplay of work and family roles. Health Psychology, 10(2), 94-101.

Barnett, R. C., Marshall, N. L., Raudenbush, S. W., \& Brennan, R. T. (1993). Gender and the relationship between job experiences and psychological distress: A study of dual-earner couples. Journal of Personality and Social Psychology, 64, 794-806.

Barusch, A. S., \& Spaid, W. M. (1989). Gender differences in caregiving: Why do wives report greater burden? The Gerontologist, 29, 667-676

Beach, S. R., Schulz, R., Yee, J. L., \& Jackson, S. (2000). Negative and positive health effects of caring for a disabled spouse: Longitudinal findings from the Caregiver Health Effects Study. Psychology and Aging, 15, 259-271.

Bigatti, S. M., \& Cronan, T. A. (2002). An examination of the physical health, health care use, and psychological well-being of spouses of people with fibromyalgia syndrome. Health Psychology, 21(2), $157-166$.

Bodenmann, G., \& Shantinath, S. D. (2004). The Couples Coping Enhancement Training (CCET): A new approach to prevention of marital stress based on stress and coping. Family Relations, 53, 477484.

Booth, A., \& Johnson, D. R. (1994). Declining health and marital quality. Journal of Marriage and the Family, 56, 218-223.

Bossé, R., Aldwin, C. M., Levenson, M. R., \& Ekerdt, D. J. (1987). Mental health differences among retirees and workers: Findings from the Normative Aging Study. Psychology and Aging, 2, 383-389.

Bossé, R., Ekerdt, D. J., \& Silbert, J. E. (1984). The Veterans Administration Normative Aging Study. In S. A. Mednick, M. Harway, \& K. M. Finello (Eds.), Handbook of longitudinal research: Volume 2. Teenage and adult cohorts (pp. 273-283). New York: Praeger.

Burman, B., \& Margolin, G. (1992). Analysis of the association between marital relationships and health problems: An interactional perspective. Psychological Bulletin, 112(1), 39-63.

Busby, D. M., Christensen, C., Crane, D. R., \& Larson, J. H. (1995). A revision of the Dyadic Adjustment Scale for use with distressed and nondistressed couples: Construct hierarchy and multidimensional scales. Journal of Marital and Family Therapy, 21, 289-308. 
Cannuscio, C. C., Jones, C., Kawachi, I., Colditz, G. A., Berkman, L., \& Rimm, E. (2002). Reverberations of family illness: A longitudinal assessment of informal caregiving and mental health. American Journal of Public Health, 92, 1305-1311.

Carey, M. P., Spector, H. P., Lantinga, L. J., \& Krauss, D. J. (1993). Reliability of Dyadic Adjustment Scale. Psychological Assessment, 5 , 238-240.

Crane, D. R., Allgood, S. M., Larson, J. H., \& Griffin, W. (1990). Assessing marital quality with distressed and nondistressed couples: A comparison and equivalency table for three frequently used measures. Journal of Marriage and the Family, 52, 87-93.

Crane, D. R., Middleton, K. C., \& Bean, R. A. (2000). Establishing criterion scores for the Kansas Marital Satisfaction Scale and the Revised Dyadic Adjustment Scale. American Journal of Family Therapy, 28, 53-60.

Eddy, J. M., Heyman, R. E., \& Weiss, R. L. (1991). An empirical evaluation of the Dyadic Adjustment Scale: Exploring the differences between marital "satisfaction" and "adjustment." Behavioral Assessment, 13, 199-220.

Grunfeld, E., Coyle, D., Whelan, T., Clinch, J., Reyno, L., Earle, C. C, et al. (2004). Family caregiver burden: Results of a longitudinal study of breast cancer patients and their principal caregivers. Canadian Medical Association Journal, 170, 1795-1801.

Hagedoorn, M., Sanderman, R., Ranchor, A. V., Brilman, E. I., Kempen, G. I. J. M., \& Ormel, J. (2001). Chronic disease in elderly couples: Are women more responsive to their spouses' health condition than men? Journal of Psychosomatic Research, 51, 693-696.

Heidrich, S. M., \& Powwattana, A. (2004). Self-discrepancy and mental health in older women with chronic illness. Journal of Adult Development, 11, 251-259.

Jang, Y., Clay, O. J., Roth, D. L., Haley, W. E., \& Mittelman, M. S. (2004). Neuroticism and longitudinal change in caregiver depression: Impact of a spouse-caregiver intervention program. The Gerontologist, 44, 311-317.

Johnson, D., White, L., Edwards, J., \& Booth, A. (1986). Dimensions of marital quality. Journal of Family Issues, 7, 31-49.

Karney, B. R., \& Bradbury, T. N. (1995). The longitudinal course of marital quality and stability: A review of theory, method, and research. Psychological Bulletin, 118, 3-34.

Kiecolt-Glaser, J. K. (1999). Stress, personal relationships, and immune function: Health implications. Brain, Behavior, and Immunity, 13, 6172.

Kiecolt-Glaser, J. K., Glaser, R., Cacioppo, J. T., \& Malarkey, W. B. (1998). Marital stress: Immunologic, neuroendocrine, and autonomic correlates. Annals of the New York Academy of Sciences, 840, 649-655.

Kiecolt-Glaser, J. K., \& Newton, T. L. (2001). Marriage and health: His and hers. Psychological Bulletin, 127, 472-503.

Kramer, B. J., \& Kipnis, S. (1995). Eldercare and work-role conflict: Toward an understanding of gender differences in caregiver burden. The Gerontologist, 35, 340-348.

Larsen, R. J., \& Kasimatis, M. (1991). Day-to-day physical symptoms: Individual differences in the occurrence, duration, and emotional concomitants of minor daily illnesses. Journal of Personality, 59, $387-423$.

Larson, J. H. (2004). Innovations in marriage education: Introduction and challenges. Family Relations, 53, 421-424.

Larson, R. W., \& Almeida, D. M. (1999). Emotional transmission in the daily lives of families: A new paradigm for studying family process. Journal of Marriage and the Family, 61, 5-20.

Lewis, M. A., Rook, K. S., \& Schwarzer, R. (1994). Social support, social control, and health among the elderly. In G. N. Penny, P. Bennett, \& M. Herbert (Eds.), Health psychology: A lifespan perspective (pp. 191211). Philadelphia: Harwood Academic.

Loeb, S. J., Penrod, J., Falkenstern, S., Gueldner, S. H., \& Poon, L. W. (2003). Supporting older adults living with multiple chronic conditions. Western Journal of Nursing Research, 25(1), 8-29.

Lyons, K. S., \& Sayer, A. G. (2005). Longitudinal dyad models in family research. Journal of Marriage and Family, 67, 1048-1060.

McNulty, J. K., \& Karney, B. R. (2001). Attributions in marriage: Integrating specific and global evaluations of a relationship. Personality and Social Psychology Bulletin, 27, 943-955.
Meeks, S., Murrell, S. A., \& Mehl, R. C. (2000). Longitudinal relationships between depressive symptoms and health in normal older and middleaged adults. Psychology and Aging, 15(1), 100-109.

Miller, R. B., Hemesath, K., \& Nelson, B. (1997). Marriage in middle and later life. In T. D. Hargrave \& S. M. Hanna (Eds.), The aging family: New vision in theory, practice, and reality (pp. 178-198). Philadelphia: Brunner/Mazel.

Neupert, S. D., Almeida, D. M., Mroczek, D. K., \& Spiro, A., III. (2006). The effects of the Columbia shuttle disaster on the daily lives of older adults: Findings from the VA Normative Aging Study. Aging \& Mental Health, 10, 272-281.

Osler, M. (1998). The food intake of smokers and nonsmokers: The role of partner's smoking behavior. Preventive Medicine: An International Journal Devoted to Practice and Theory, 27, 438-443.

Patterson, J., \& Garwick, A. (1994). The impact of chronic illness on families: A family systems perspective. Annals of Behavioral Medicine, 16, $131-142$.

Pinquart, M., \& Sörensen, S. (2005). Ethnic differences in stressors, resources, and psychological outcomes of family caregiving: A meta-analysis. The Gerontologist, 45, 90-106.

Prigerson, H. G., Maciejewski, P. K., \& Rosenheck, R. A. (2002). Population attributable fractions of psychiatric disorders and behavioral outcomes associated with combat exposure among US men. American Journal of Public Health, 92, 59-63.

Raudenbush, S. W., Brennan, R. T., \& Barnett, R. C. (1995). A multivariate hierarchical model for studying psychological change within married couples. Journal of Family Psychology, 9, 161-174.

Rolland, J. S., \& Walsh, F. (2005). Systemic training for healthcare professionals: The Chicago Center for Family Health approach. Family Process, 44, 283-301.

Rosenberg, S. J., Hayes, J. R., \& Peterson, R. A. (1987). Revising the seriousness of illness rating scale: Modernization and re-standardization. International Journal of Psychiatry in Medicine, 17(1), 85-92.

Schmalling, K. B., \& Sher, T. G. (2000). The psychology of couples and illness. Washington, DC: American Psychological Association.

Schulz, R., Visintainer, P., \& Williamson, G. M. (1990). Psychiatric and physical morbidity effects of caregiving. Journal of Gerontology: Psychological Sciences, 45(5), P181-P191.

Sherliker, L., \& Steptoe, A. (2000). Coping with new treatments for cancer: A feasibility study of daily diary measures. Patient Education and Counseling, 40, 11-19.

Snijders, T. A. B., \& Bosker, R. (1999). Multilevel analysis. Thousand Oaks, CA: Sage.

Spanier, G. (1976). Measuring dyadic adjustment: New scales for assessing the quality of marriage and similar dyads. Journal of Marriage and the Family, 38, 15-28.

VanLaningham, J., Johnson, D. R., \& Amato, P. (2000). Marital happiness, marital duration, and the u-shaped curve: Evidence from a fivewave panel study. Social Forces, 79, 1313-1341.

Vilhjalmsson, R. (1998). Direct and indirect effects of chronic physical conditions on depression: A preliminary investigation. Social Science \& Medicine, 47, 603-611.

Watson, D. (1988). Intraindividual and interindividual analyses of positive and negative affect: Their relation to health complaints, perceived stress, and daily activities. Journal of Personality and Social Psychology, 54, 1020-1030.

Watson, D., Clark, L. A., \& Tellegen, A. (1988). Development and validation of brief measures of positive and negative affect: The PANAS scales. Journal of Personality and Social Psychology, 54, 1063-1070.

Wickrama, R. A. S., Lorenz, F. O., Conger, R. D., \& Elder, G. H. (1997). Marital quality and physical illness: A latent growth curve analysis. Journal of Marriage and the Family, 59, 143-155.

\section{Appendix A}

Equations for wife and husband affect and betweenand within-person physical symptoms (example of moderation by baseline marital satisfaction). 


$$
\begin{aligned}
\mathrm{Y}_{t i k}= & (\text { WPos})\left[\mathrm{a}_{0 i 1}+\mathrm{a}_{1 i 1}\left(\mathrm{WS}_{t i}-\text { MeanWS }_{i}\right)\right. \\
& \left.+\mathrm{a}_{2 i 1}\left(\mathrm{HS}_{t i}-\mathrm{MeanHS}_{i}\right)\right]+e_{t i 1} \\
& +(\mathrm{WNeg})\left[\mathrm{a}_{0 i 2}+\mathrm{a}_{1 i 2}\left(\mathrm{WS}_{t i}-\text { MeanWS }_{i}\right)\right. \\
& \left.+\mathrm{a}_{2 i 2}\left(\mathrm{HS}_{t i}-\text { Mean HS }_{i}\right)\right]+e_{t i 2} \\
& +(\mathrm{HPos})\left[\mathrm{a}_{0 i 3}+\mathrm{a}_{1 i 3}\left(\mathrm{HS}_{t i}-\text { MeanHS }_{i}\right)\right. \\
& \left.+\mathrm{a}_{2 i 3}\left(\mathrm{WS}_{t i}-\text { Mean WS }_{i}\right)\right]+e_{t i 3} \\
& +(\mathrm{HNeg})\left[\mathrm{a}_{0 i 4}+\mathrm{a}_{1 i 4}\left(\mathrm{HS}_{t i}-\text { Mean HS }_{i}\right)\right. \\
& \left.+\mathrm{a}_{2 i 4}\left(\mathrm{WS}_{t i}-\text { Mean WS }_{i}\right)\right]+e_{t i 4} \\
\mathrm{a}_{0 i 1}= & \beta_{001}+\beta_{011}\left(\text { MeanWS }_{i}\right)+\beta_{021}\left(\text { MeanHS }_{i}\right) \\
& +\beta_{031}\left(\mathrm{WMarSat}_{i}\right)+\beta_{041}\left(\text { HMarSat }_{i}\right)+\mathrm{U}_{0 i 1} \\
\mathrm{a}_{0 i 2}= & \beta_{002}+\beta_{012}\left(\text { MeanWS }_{i}\right)+\beta_{022}\left(\text { MeanHS }_{i}\right) \\
& +\beta_{032}\left(\text { WMarSat }_{i}\right)+\beta_{042}\left(\text { HMarSat }_{i}\right)+\mathrm{U}_{0 i 2} \\
\mathrm{a}_{0 i 3}= & \beta_{003}+\beta_{013}\left(\text { MeanHS }_{i}\right)+\beta_{023}\left(\text { Mean WS }_{i}\right) \\
& +\beta_{033}\left(\text { HMarSat }_{i}\right)+\beta_{043}\left(\text { WMarSat }_{i}\right)+\mathrm{U}_{0 i 3} \\
\mathrm{a}_{0 i 4}= & \beta_{004}+\beta_{014}\left(\text { MeanHS }_{i}\right)+\beta_{024}\left(\text { Mean WS }_{i}\right) \\
& +\beta_{034}\left(\text { HMarSat }_{i}\right)+\beta_{044}\left(\text { WMarSat }_{i}\right)+\mathrm{U}_{0 i 4}
\end{aligned}
$$

$$
\begin{aligned}
& \mathrm{a}_{1 i 1}=\beta_{101} ; \mathrm{a}_{122}=\beta_{102} ; \mathrm{a}_{1 i 3}=\beta_{103} ; \mathrm{a}_{1 i 4}=\beta_{104} ; \\
& \mathrm{a}_{2 i 1}=\beta_{201}+\beta_{211}\left(\text { HMarSat }_{i}\right) ; \\
& \mathrm{a}_{2 i 2}=\beta_{202}+\beta_{212}\left(\text { HMarSat }_{i}\right) ; \\
& \mathrm{a}_{2 i 3}=\beta_{203}+\beta_{213}\left(\text { WMarSat }_{i}\right) ; \\
& \mathrm{a}_{2 i 4}=\beta_{204}+\beta_{214}\left(\text { WMarSat }_{i}\right) .
\end{aligned}
$$

At Level 1, $Y_{t i k}$ and the $e$ 's represent the outcome $\mathrm{Y}$ and residual deviation from $\mathrm{Y}$, respectively, for time $t$, couple $i$, and measure $k$. WPos, WNeg, HPos, and HNeg are dummy codes that equal 1 for wife positive mood, wife negative mood, husband positive mood, and husband negative mood, respectively, and 0 otherwise. Thus, when multiplied by each dummy code, only the coefficients in the parentheses corresponding to each outcome (as indexed by $k$ ) will contribute to the predicted value for that outcome. $\mathrm{WS}_{t i}$ and $\mathrm{HS}_{t i}$ represent the wives' and husbands' symptoms, respectively, for time $(t)$ and couple (i). Mean $\mathrm{WS}_{i}$ and Mean $\mathrm{HS}_{i}$ represent the average symptoms over the 8 days for wives and husbands, respectively. At Level 1, the predicted value for each type of mood and for each person is a function of the individual intercept (the $\mathrm{a}_{0 i}$ 's), plus the contribution of the deviation from one's own average daily symptoms (the $\mathrm{a}_{1 i}$ 's), plus the contribution of one's spouse's deviation from average daily symptoms (the $\mathrm{a}_{2 i}$ 's). At Level 2, the individual intercepts are a function of the expected value for the sample (the $\beta_{00}$ 's), plus the contribution of one's own average daily symptoms (the $\beta_{01}$ 's), plus the contribution of one's spouse's average daily symptoms (the $\beta_{02}$ 's), plus the contribution of one's own marital satisfaction (the $\beta_{03}$ 's), plus the contribution of one's spouse's marital satisfaction (the $\beta_{04}$ 's), plus a random person-specific deviation from the sample average (the $\mathrm{U}_{0 i}$ 's). The effect of one's own daily symptoms (the $a_{1 i}$ 's) is fixed for the sample (the $\beta_{10}$ 's). The effect of one's spouse's daily symptoms (the $\mathrm{a}_{2 i}$ 's) is a function of the expected value for the sample (the $\beta_{20}$ 's), plus the contribution of one's spouse's marital satisfaction (the $\beta_{21}$ 's). Thus, the relationship between spousal symptoms and mood is moderated by spousal marital satisfaction. A comparable model also is estimated in which chronic illness severity was the Level 2 moderator. 